\title{
Bioactive Compounds of Chamber-Dried Blueberries at Controlled Temperature and Wines Obtained from Them
}

\author{
Juan Martin-Gomez, M. Angeles Varo, Julieta Merida, and Maria P. Serratosa \\ Departamento de Química Agrícola, Facultad de Ciencias, Universidad de Córdoba, Edificio Marie Curie, \\ Campus de Rabanales, 14014 Córdoba, Spain \\ Correspondence should be addressed to Maria P. Serratosa; mpserratosa@uco.es
}

Received 3 April 2017; Revised 8 August 2017; Accepted 14 September 2017; Published 16 October 2017

Academic Editor: Wieslaw Wiczkowski

Copyright (C) 2017 Juan Martin-Gomez et al. This is an open access article distributed under the Creative Commons Attribution License, which permits unrestricted use, distribution, and reproduction in any medium, provided the original work is properly cited.

The effects of chamber drying under controlled temperature and moisture conditions and fermentation process on blueberry juices to obtain three wines were studied in this work. Drying was carried out with a view to increase the sugar content and obtain wines with an ethanol content similar to a commercial grape wine or to obtain sweet wines. Analyses included color parameters; browning index; and anthocyanin, flavonols, flavan-3-ol derivatives, and tannin concentrations, as well as vitamin $\mathrm{C}$ concentration and antioxidant activity. Based on the results, drying increases color and the concentration of anthocyanins and tannins most probably by the effect of dehydration of the berries and diffusion of the colored compounds from the skin to the pulp due to the structural alterations in their skin. In addition, drying decreases flavonols, flavan-3-ol derivatives, and vitamin $\mathrm{C}$ concentrations. The browning index, anthocyanins, and tannins decreased with the fermentation time, and vitamin $\mathrm{C}$ was constant with the fermentation time. The sensory analysis showed that the wines with the best sensory characteristics were those with residual sugar, partial fermented wines 1 and 2.

\section{Introduction}

Blueberries, Vaccinium corymbosum, are native to eastern North America and southeastern Canada [1]; however, they are extending to Europe, Asia, Africa, and Australia. Blueberries can be consumed as fresh fruits and also in products derived as seasoning products of bakery, pastry filling, juices, yogurt, and so forth [2]. Besides, in the last years, the use of different berries for the elaboration of fermented beverages or wines has spread, principally due to the fact that grapes are not well cultivated in every region of the world. Another type of fruit is used to carry out the fermentation process, with the berries of red fruits being some of the most used due to their phenolic composition, especially in anthocyanins content [3]. Yan et al. [4] have studied the optimal conditions of blueberries juice fermentation, with these conditions being a temperature of $22.65^{\circ} \mathrm{C}$ and a $\mathrm{pH}$ of 3.53 . They carried out the fermentation of the blueberry juice adding sucrose, to reach the alcoholic graduation of a standard wine. Nevertheless, other authors have developed direct fermentation on the juice, reaching only $5-6 \%$ of alcohol, due to the concentration of sugar $[5,6]$.

Blueberries are functional food due to their health benefits (e.g., antioxidant, anti-inflammation, neuroprotection, antimetastatic, cardioprotective, antimicrobial, renoprotective, opthalmoprotective, antidiabetic, hepatoprotective, gastroprotective, antiosteoporotic, and antiaging) [7]. These properties are consequent of their phenolic composition [8]. The protective activity is attributed to their antioxidant capacity and free radical scavenger in addition to the ability to inhibit and reduce enzymes [9]. The phenolic compounds of blueberries include anthocyanins (anthocyanidins glycosides) which are in the cell vacuoles in the red fruit skins [10]. They are responsible for the fruit color, between red and blue characteristic of blueberry. Flavonols are a flavonoid family ranging from white to yellow in color depending on their structure, but in red wines they can participate in the color because they are copigments of anthocyanins [11]. Flavan-3-ol derivatives are flavonoid compounds with optical isomerism; $(+)$-catechin and $(-)$-epicatechin are the most 
representative, and they are found in the seeds and stems of the grapes [12]. Tannins encompass a series of phenolic compounds, including condensed tannins (namely, variably complex polymers of flavan-3-ol) and hydrolysable tannins (ellagitannins and gallotannins, mainly); they are highly astringent and bitter compounds present in seeds of fruits.

The addition of sucrose is the most common method to increase the sugar content of blueberry juices [13-15] to obtain a fermented beverage with a standard ethanol content. Nevertheless, the partial dehydration of the berry can increase the sugar content in a similar way to that made in southern Spain or Italy for the production of sweet wines. Sun-drying is the most traditional drying method, but artificial drying with controlled temperature, relative humidity, and air flow had some advantages [16] such as avoiding losses for the weather (rain) or the attack of insects and fungi. These methods affect the berry's properties such as color, texture, and density [17].

The aim of this work was to evaluate the changes in bioactive compounds, color, and antioxidant activity during the drying process and subsequent fermentation of sugar-rich juices to obtain blueberry wines.

\section{Materials and Methods}

2.1. Reagents. Hydrochloric acid, metaphosphoric acid, formic acid, acetic acid, methanol, acetonitrile, sodium metabisulphite, potassium chloride, sodium acetate, acid potassium dichromate, ethyl acetate, and potassium dihydrogen phosphate were purchased from Merck (Madrid, Spain). Anthocyanins (malvidin-3-O-galactoside chloride), flavan-3-ol derivative $((+)$-catechin, $(-)$-epicatechin, epigallocatechin gallate, procyanidin $\mathrm{B} 1$, and procyanidin $\mathrm{B} 2$ ), Trolox (6-hydroxy-2,5,7,8-tetramethylchroman-2-carboxylic acid), DPPH (2,2-diphenylpicrylhydrazyl), and DTT (DLdithiothreitol) were purchased from Sigma-Aldrich Chemical Co. (Madrid, Spain).

2.2. Blueberry Drying. The blueberries used for this study were Star variety (Vaccinium corymbosum) and they were harvested in 2015 in Moguer (Huelva, Spain) at the usual state of maturity for commercialization. One portion was crushed for analysis.

Three batches of blueberries were dried in a Frisol Climatronic chamber at a constant temperature of $40^{\circ} \mathrm{C}$ and an initial relative humidity of $20 \%$. During the drying process, a sample was collected daily and the weight loss and reducing sugar concentration of the blueberries were measured using a refractometer, model Atago Master.

The drying process was finished when the reducing sugar content reached approximately $24.2^{\circ}$ Brix. The blueberries were pressed on a vertical press similar to industrial models, obtaining the final juice. The maximum pressure reached in each of the two pressing cycles was 300 bar. The musts were centrifuged at $5000 \mathrm{rpm}$, filtered, and analyzed in triplicate.

2.3. Fermentation Process. The sweet juice was divided into three batches and was mixed with the solid parts of the berries in a ratio of $1: 1(\mathrm{w} / \mathrm{v})$. The mix was added with a yeast inoculum of commercial Saccharomyces cerevisiae in a dose recommended by the manufacturer $(0.3 \mathrm{~g} / \mathrm{L})$. The flasks were immersed in thermostatized water baths at $22 \pm 0.5^{\circ} \mathrm{C}$ [4]. Three wines were elaborated in triplicate from the dried blueberries.

Wine 1. The mix was partially fermented to $6 \%$ of ethanol $(\mathrm{v} / \mathrm{v})$ and the process was stopped by the addition of wine alcohol up to $17 \%(\mathrm{v} / \mathrm{v})$.

Wine 2. The mix was partially fermented to $14 \%$ of ethanol $(\mathrm{v} / \mathrm{v})$ and the process was stopped by the addition of wine alcohol up to $17 \%(\mathrm{v} / \mathrm{v})$.

Wine 3. The mixture was completely fermented, obtaining a wine with a $17 \%(\mathrm{v} / \mathrm{v})$ ethanol content.

After fermentation/maceration, the berries were pressed a second time on a vertical press and skin residues were removed from the wine. The resulting wines were centrifuged at $5000 \mathrm{rpm}$, filtered, and analyzed in triplicate.

2.4. Reducing Sugars. This parameter was determined according to the EEC official methods as described in Regulation 2676/1990 [18].

2.5. Volatile Acidity. Isolation of volatile acids is carried out according to the method of the OIV [19] by steam distillation and rectification of the distillate.

2.6. Spectrophotometric Determinations. Spectrophotometric measurements were made on a PerkinElmer (Waltham, MA) Lambda 25 spectrophotometer, using quartz cells of $1 \mathrm{~mm}$ light path. Samples were previously passed through Millipore (Billerica, MA) HA filters of $0.45 \mu \mathrm{m}$ pore size. All measurements were corrected for a path length of $1 \mathrm{~cm}$.

Absorbances at 420,520, and $620 \mathrm{~nm}$ were measured. Hue indicates the proportion between orange and red colors; $A 420$ and $A 520 \mathrm{~nm}$ relation was calculated.

2.6.1. Polymeric Pigments Color (PPC). To obtain PPC values, $5 \mathrm{~mL}$ of wine was added with $15 \mathrm{mg}$ of $\mathrm{Na}_{2} \mathrm{~S}_{2} \mathrm{O}_{5}$; after $45 \mathrm{~min}$, the absorbance at $520 \mathrm{~nm}$ was measured. Anthocyanin monomers were immediately decolorized by the excess $\mathrm{Na}_{2} \mathrm{~S}_{2} \mathrm{O}_{5}$ added, so the residual color was due to the polymeric forms of the pigments.

2.6.2. Antioxidant Activity. Antioxidant activity was analyzed through the DPPH assay according to Alén-Ruiz et al. [20] with some modifications. The juice and wines were diluted at 1:5 with distilled water. A $45 \mathrm{mg} / \mathrm{L}$ solution of $\mathrm{DPPH}$ (2,2-diphenylpicrylhydrazyl) in methanol was prepared on a daily basis and stored in the dark. An $80 \mathrm{mg} / \mathrm{L}$ solution of Trolox (6-hydroxy-2,5,7,8-tetramethylchroman-2-carboxylic acid), a vitamin $\mathrm{E}$ analog, was used as a standard. The analytical procedure was as follows: a $200 \mu \mathrm{L}$ aliquot of diluted sample was placed in a cell and $3 \mathrm{~mL}$ of a $45 \mathrm{mg} / \mathrm{L}$ solution of DPPH in methanol was then added. A blank ( $200 \mu \mathrm{L}$ diluted sample $+3 \mathrm{~mL}$ methanol), a control sample ( $200 \mu \mathrm{L}$ of $12 \%$ ethanol in water $+3 \mathrm{~mL}$ of DPPH solution), and a Trolox standard $(200 \mu \mathrm{L}$ of Trolox solution $+3 \mathrm{~mL}$ of 
DPPH solution) were also prepared in parallel. Following vigorous stirring, the absorbances at $517 \mathrm{~nm}$ of the control sample and blank were measured in a PerkinElmer (Waltham, MA) Lambda 25 spectrophotometer. The sample and the Trolox standard were measured under identical conditions after $120 \mathrm{~min}$ of incubation at room temperature. The results were expressed in millimoles of Trolox per liter.

Antioxidant activity (mmol TE/L)

$$
\begin{aligned}
& =\frac{\left(0,32 \cdot A_{1} \cdot \text { dilution factor }\right)_{2}}{A_{2}} \\
A_{1} & =\text { Absorbance }_{\text {control }(t=0)}-\text { Absorbance }_{\text {sample }}, \\
A_{2} & \\
\quad= & \text { Absorbance }_{\text {control }(t=0)}-\text { Absorbance }_{\text {standard }(t=120)}, \\
\text { Absorbancia }_{\text {sample }} & \text { Absorbancia }_{\text {sample }(t=120)}-\text { Absorbancia }_{\text {blanc }(t=0)} .
\end{aligned}
$$

2.6.3. Total Anthocyanins. The total monomeric anthocyanin pigment content was measured by the $\mathrm{pH}$ differential method described by Lee et al. [21]. This method is based on the change of the maximum of absorbance with a change in $\mathrm{pH}$ of the monomeric anthocyanins. Two dilutions at $1: 10$ of juice samples were prepared with $\mathrm{pH} 1.0$ buffer (potassium chloride) and $\mathrm{pH} 4.5$ buffer (sodium acetate) and the absorbance was measured at 500 and $720 \mathrm{~nm}$ within 20-50 minutes of preparation. Calculate total anthocyanin concentration, expressed as cyanidin-3-glucoside equivalents, as follows:

Total monomeric anthocyanins $(\mathrm{mg} / \mathrm{L})$

$$
\begin{aligned}
= & \frac{A \cdot M_{W} \cdot D \cdot 1000}{\varepsilon \cdot \mathrm{LP}} \\
& \quad A=\left(A_{520}-A_{700}\right)_{\mathrm{pH} 1}-\left(A_{520}-A_{700}\right)_{\mathrm{pH} 4,5},
\end{aligned}
$$

where $M_{W}$ is the molecular weight of cyanidin-3-glucoside $(449.2 \mathrm{~g} / \mathrm{mol}), D$ is the dilution factor, $\varepsilon$ is molar extinction coefficient for cyanidin-3-glucoside $(26900 \mathrm{~L} / \mathrm{mol} \cdot \mathrm{cm})$, and LP is the light path.

2.6.4. Total Tannins. The total tannins were determined by measurement of the absorbance at $550 \mathrm{~nm}$ after acid hydrolysis of the samples diluted at 1:50 with distilled water and a blank. The resulting absorbance $\left(A_{\text {sample }}-A_{\text {blank }}\right)$ was multiplied by a factor of 19.33 , in order to calculate the total tannin concentration, in $\mathrm{g} / \mathrm{L}$.

2.6.5. Ethanol Content. Ethanol content was determined according to Crowell and Ough [22]; to this end, ethanol in the sample was collected by steam and then reacted with acid potassium dichromate. The reaction was spectrophotometrically monitored via the absorbance at $600 \mathrm{~nm}$ against a blank on a PerkinElmer Lambda 25 spectrophotometer.

2.7. Flavonols Extraction. A volume of $2 \mathrm{~mL}$ of must was passed through a Sep-Pak C18 cartridge, with $900 \mathrm{mg}$ of filling (Long Body Sep-Pak Plus; Waters Associates, Milford, Massachusetts) that was previously activated with $5 \mathrm{~mL}$ of pure methanol and washed with aqueous $0.01 \%(\mathrm{v} / \mathrm{v}) \mathrm{HCl}$. The cartridge was successively washed with $10 \mathrm{~mL}$ of $0.01 \%$ aqueous $\mathrm{HCl}$. The cartridge was eluted with $5 \mathrm{~mL}$ of pure ethyl acetate. This collected fraction was evaporated on a rotary evaporator thermostated at $35^{\circ} \mathrm{C}$ and resolved in $1 \mathrm{~mL}$ of pure methanol. The fraction was passed through a filter of $0.45 \mu \mathrm{m}$ pore size before injection into the HPLC instrument.

2.8. Identification and Quantification of Flavonols by HPLC$D A D$. A volume of $50 \mu \mathrm{L}$ of the sample was injected into an HPLC-DAD instrument (Beckman Coulter System Gold, 168 Detector) and the analyses were carried out on a LiChrospher $100 \mathrm{RP}-18$ column $(250 \mathrm{~mm} \times 4.6 \mathrm{~mm}, 5 \mu \mathrm{m})$, according to the method proposed by Marquez et al. [23]. The identification was carried out by comparing their retention times with those for standards, recording UV-Vis spectra, and calculating the UV absorbance ratios for samples and standards simultaneously coinjected one at a time.

2.9. Identification and Quantification of Flavan-3-ol Derivatives. In the case of identification and quantification of flavan-3-ol derivatives, the samples were diluted 25 times in ultrapure water. The identification and quantification were carried out in an HPLC (Thermo Spectra Physics Series P100) with a fluorescence detector (PerkinElmer Series 200a), on a LiChrospher $100 \mathrm{RP}-18$ column $(250 \mathrm{~mm} \times 4.6 \mathrm{~mm}, 5 \mu \mathrm{m})$, according to the method proposed by Marquez et al. [23].

2.10. Vitamin C. $0.7 \mathrm{~mL}$ of $4.5 \%$ metaphosphoric acid was added to $0.7 \mathrm{~mL}$ of juice, and the mix was centrifuged at $5000 \mathrm{rpm}$ for 10 minutes at $4^{\circ} \mathrm{C} .1 \mathrm{~mL}$ of the mix was added to $0.2 \mathrm{~mL}$ of DTT (DL-dithiothreitol) solution and the sample was kept in the dark for 2 hours in order to reduce the dehydroascorbic acid to L-ascorbic acid. After complete conversion, the sample was filtered with a nylon filter of $0.45 \mu \mathrm{m}$ pore size. Ascorbic acid quantification was performed on an HPLC chromatograph (Thermo Spectra Physics Series P100) coupled to a UV detector (Thermo Finnigan Spectra System UV2000), using a LiChrospher $100 \mathrm{RP}-18$ column $(250 \mathrm{~mm} \times 4.6 \mathrm{~mm}, 5 \mu \mathrm{m}) . \mathrm{KH}_{2} \mathrm{PO}_{4}(0.2 \mathrm{M}$ at $\mathrm{pH}=2.3-2.4$ ) was used as a mobile phase with a flow of $1.0 \mathrm{~mL} / \mathrm{min}$ for 15 minutes at $\lambda=243 \mathrm{~nm}$ and an injection volume of $20 \mu \mathrm{L}$.

2.11. Sensory Analysis of Wines. The wines were assessed for aroma, flavor, and color acceptability in accordance with ISO 8586-1:1993. The tasting room was kept at $20^{\circ} \mathrm{C}$ and wines were served in coded tasting glasses certified in accordance with ISO 3591:1977. The sixteen tasters were instructed in advance in their task and the rules to be followed and were given a scoring sheet. The evaluation of the quality of wines was made according to ISO 4121:2003, with options of desirable (5-6), acceptable (3-4), and undesirable (1-2).

2.12. Statistical Procedures. The results for all samples were subjected to analysis of variance at the $95.0 \%$ confidence level; in addition, homogeneous groups were calculated in 


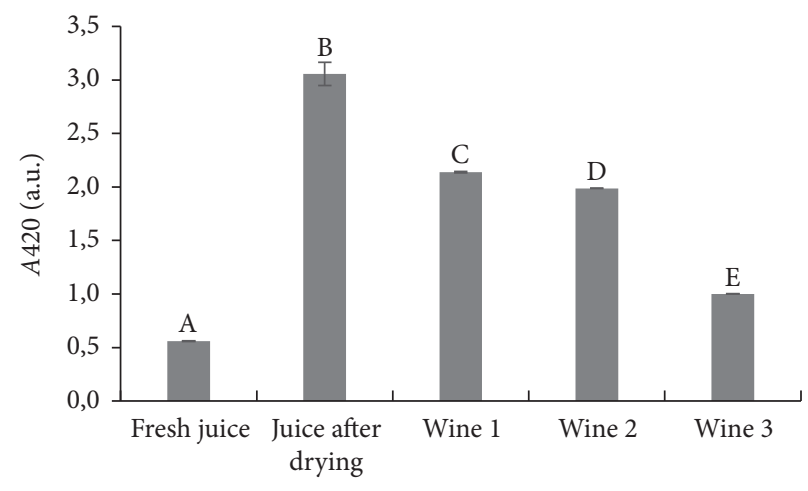

(a)

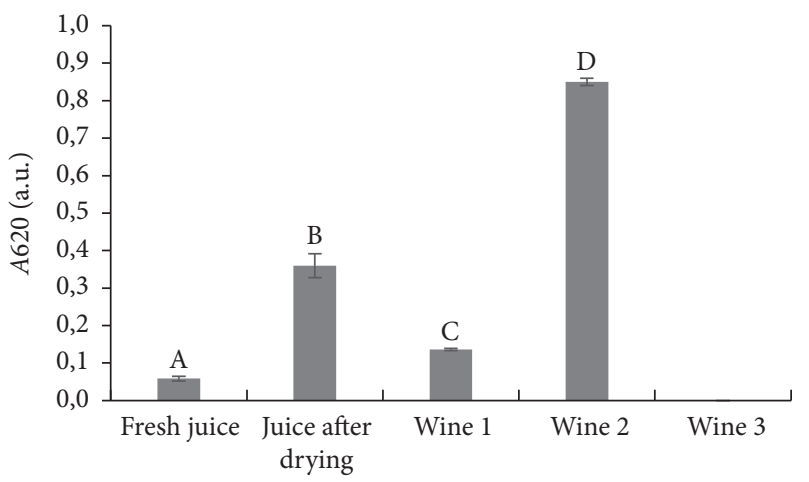

(c)

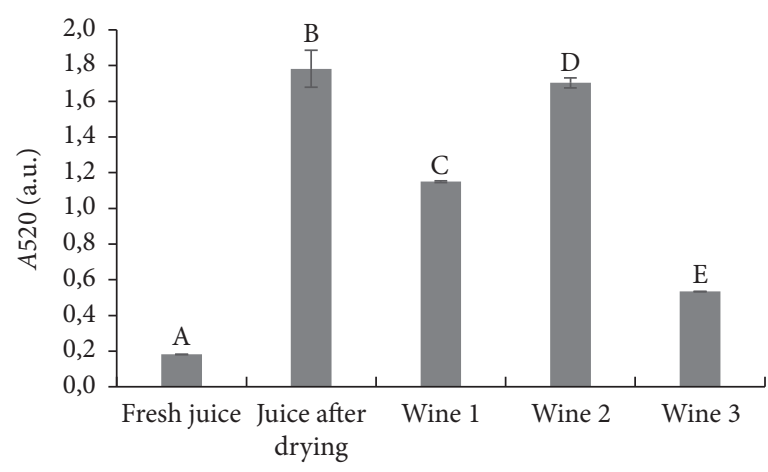

(b)

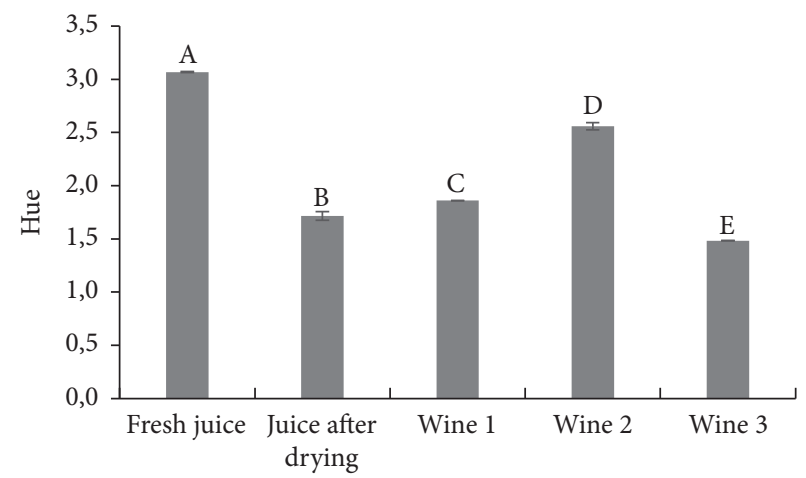

(d)

Figure 1: Changes in (a) absorbance at $420 \mathrm{~nm}$ (a.u.), (b) absorbance at $520 \mathrm{~nm}$ (a.u.), (c) absorbance at $620 \mathrm{~nm}$ (a.u.), and (d) hue for blueberry juices and wines. $N=3$. Columns with different superscript letters are significantly different, $p=0.05$.

order to establish significant differences between means. The software used was the Statgraphics Computer Package v.5.0 from Statistical Graphics Corp.

\section{Results and Discussion}

The first stage in the elaboration of blueberry wine was a drying process in order to increase the sugar content to obtain a fermented beverage with an ethanol content similar to a grape wine. The blueberry variety presented a sugar content of $13.2^{\circ}$ Brix. This content increased to $24.2^{\circ}$ Brix after 48 hours of drying. During the drying process, evaporation of water occurred, causing the concentration of other compounds besides the sugars. A sweet juice was obtained from the dried blueberries and this juice was subjected to a fermentation process obtaining three wines with different sugar contents due to the different times of fermentation. Wine 1 was a sweet wine with $117 \mathrm{~g} / \mathrm{L}$ of residual sugars, wine 2 was a semisweet wine $(28.8 \mathrm{~g} / \mathrm{L}$ of residual sugars), and wine 3 was a dry wine $(0 \mathrm{~g} / \mathrm{L}$ of residual sugars).

The volatile acidity was measured in order to control the quality of wines. This parameter represents the amount of volatile acids in the wines, acetic acid being the majority. The volatile acidity increased with the fermentation time with values of $5.4,5.9$, and $8.9 \mathrm{meq} / \mathrm{L}$ for wine 1 , wine 2 , and wine 3 , respectively. The latter presented a value higher than the limit established in the Official State Bulletin [24] for commercial grape wines.
Color is the first attribute perceived by the consumer in food. The absorbances at 420,520 , and $620 \mathrm{~nm}$ as well as the hue were measured and expressed as absorbance units (a.u.). These three absorbances represent the contribution of browning and red and blue compounds, respectively. As can be seen in Figure 1, the absorbances increased in the drying process, so the color intensity of the juice from dried fruits was higher than of the juice from fresh fruits. In relation to wines, the browning index $(A 420)$ decreased with the fermentation time; wine 3 presented the lowest value. The values of absorbances at 520 and $620 \mathrm{~nm}$ were the highest in wine 2; wine 3 presented the lowest values of both absorbances. This may be a result of the adsorption of colored compounds by the cell walls of the yeasts [25]. The hue, expressed as the ratio between absorbances at 420 and $520 \mathrm{~nm}$ (Figure 1(d)), decreased in the drying process, although the values were always above value 1 , which indicates greater contribution of the brown compounds. In wines, wine 3 (total fermentation) was the beverage with the lowest value.

The polymeric pigments color measured in wines shows that the fermentation process produced a decrease of PPC with time $(0.699,0.517$, and 0.373 in wine 1 , wine 2 , and wine 3 , resp.), so the contribution of pigment polymers to color decreases. On the one hand, the high value of wine 1 was due to the concentration resulting from the loss of water by evaporation during the drying process. On the other hand, the maceration with solid parts should increase the values 


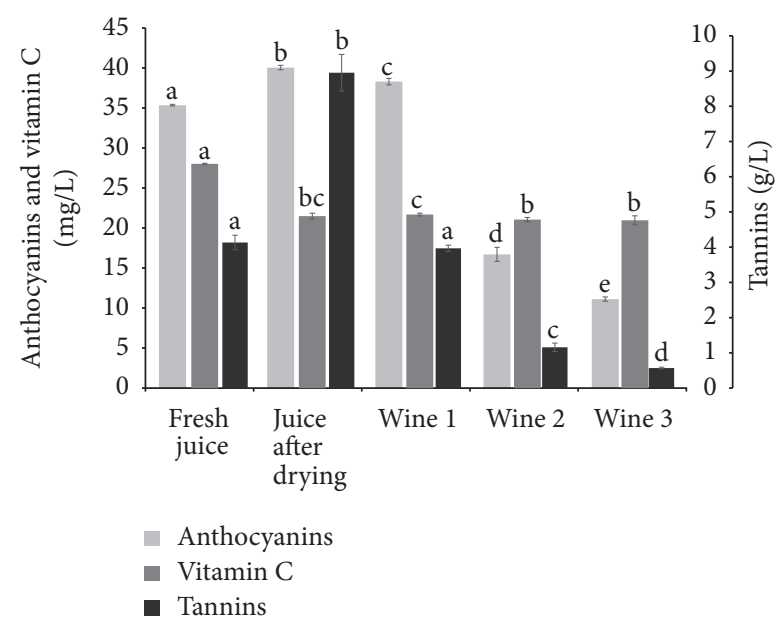

FIGURE 2: Changes in anthocyanins, vitamin $C$, and tannins of blueberry juices and wines. $N=3$. Columns of the same parameter with different superscript letters are significantly different, $p=0.05$.

during the fermentation. Nevertheless, these compounds decreased during the maceration, possibly due to other reactions in which they may be involved.

Anthocyanins are polyphenolic pigments which are responsible for the red color of blueberry juices and wines. The drying process increased the concentration of these compounds due to the water evaporation and the diffusion process from skin to juice due to the structural alterations in fruit skin [26]. After the drying, the anthocyanins content was $40 \mathrm{mg} / \mathrm{L}$ (Figure 2). In wines, the concentration of monomer anthocyanins decreased with the fermentation time, with wine 3 presenting the lowest concentration. This fact could be due to, on the one hand, the adsorption of anthocyanin by the cell membranes of yeast; as the time of contact with yeasts increases, a reduction of these compounds occurs in the juice [25]. Furthermore, condensation reactions occur between the monomeric anthocyanins and some yeast metabolites resulting in new compounds called pyranoanthocyanins [27] or condensation reactions with other phenolic compounds such as flavonols and flavans [28].

Regarding the concentration of total vitamin $\mathrm{C}$, fresh blueberries showed the highest value (28.1 mg/L) (Figure 2). The drying process produced a decrease in total vitamin $\mathrm{C}$ content to $21.5 \mathrm{mg} / \mathrm{L}$. This vitamin C concentration was maintained without significant changes during the fermentation process. Vitamin $\mathrm{C}$ is a typical heat sensitive micronutrient, so the decrease during the drying process is due to the temperature [29]. Then, the fermentation process did not affect the content of this vitamin.

Tannins are polymer compounds responsible for the astringency of wines. In wines, certain astringency is appreciable, although if it is excessive it becomes a defect. Drying process raised its content from 4.13 to $8.95 \mathrm{~g} / \mathrm{L}$ (Figure 2), due mainly to the concentration effect by water evaporation. However, the fermentation process produced a decrease in total tannin values, which was more pronounced as the fermentation time increased. The final values of the wines

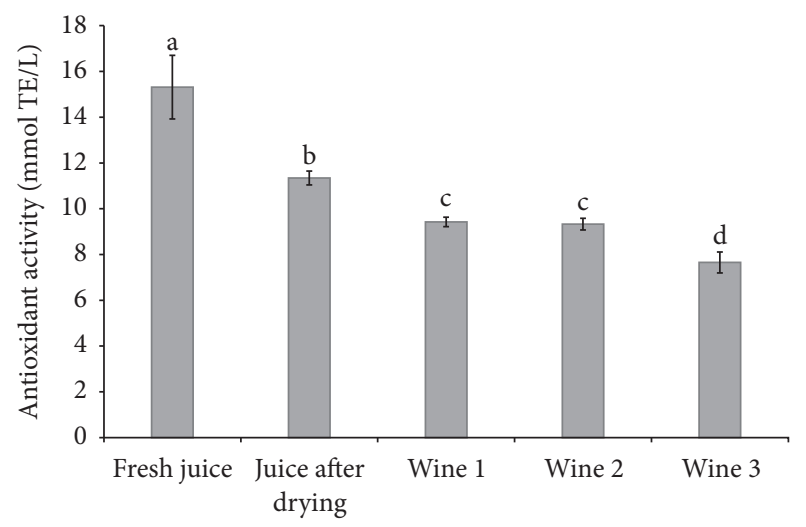

FIgURE 3: Antioxidant activity for blueberry juices and wines. $N=3$. Columns with different superscript letters are significantly different, $p=0.05$.

were $3.97 \mathrm{~g} / \mathrm{L}$ in wine 1 (less fermentation time) and 1.15 and $0.570 \mathrm{~g} / \mathrm{L}$ in wine 2 and wine 3 , respectively. This fact can be contrary in other fermentation processes where tannins content increased due to the effect of their synthesis and/or extraction in an ethanol medium. Tannins in grape seeds are slowly dissolved during maceration as the cuticle is dissolved in ethanol; by contrast, tannins in grape skins were extracted more rapidly by the effect of their ready dissolution in the aqueous phase [30].

Table 1 shows the concentrations of flavonols and flavan3-ol derivatives in blueberry juices and wines. Four flavonols were identified: two quercetin derivatives and two syringetin derivatives. Quercetin derivatives presented higher concentrations than those of syringetin in the juice from fresh fruit; in addition, the galactose derivatives were found in higher concentration in both cases. The drying process decreased the concentration of these phenolic compounds. Some authors found out that the drying process increases the concentration of flavonols [23]. During the fermentation process, a maceration process occurs with the berry skins, so these compounds should be extracted from skins; however, the concentration decreased, and this reduction can be ascribed to copigmentation reactions with anthocyanins [11]. The final concentration in wines is a balance between the extraction from skins and the reactions with other compounds, obtaining wine 2 with the highest flavonol concentration.

Also, five flavan-3-ol derivatives were identified and quantified: 3 monomers and 2 procyanidins. The major compound in juice from fresh fruit was procyanidin B1 followed by catechin. Drying and fermentation stages caused a decrease in concentration of total flavan-3-ol derivatives, although procyanidin $\mathrm{B} 1$ increased during drying and epicatechin could be quantified. These compounds are involved in different reactions. Catechins and proanthocyanidins are the main substrates for condensation with monomeric anthocyanins and their subsequent evolution to polymeric anthocyanins [31].

Figure 3 shows the values of antioxidant activity measured by DPPH assay in juices and wines from blueberries. As can be seen, the juice from fresh fruit had a high 
TABLE 1: Flavan-3-ol and flavonols concentrations (mg/L) and homogenous groups for blueberry juices and wines at different fermentation times.

\begin{tabular}{|c|c|c|c|c|c|}
\hline & Fresh juice & Juice after drying & Wine 1 & Wine 2 & Wine 3 \\
\hline Quercetin-3-O-galactoside & $10.6 \pm 0.862^{\mathrm{a}}$ & $4.93 \pm 0.232^{\mathrm{b}}$ & $1.87 \pm 0.104^{c}$ & $2.18 \pm 0.044^{\mathrm{c}}$ & $1.88 \pm 0.011^{\mathrm{c}}$ \\
\hline Quercetin-3-O-glucoside & $7.13 \pm 1.03^{\mathrm{a}}$ & $4.04 \pm 0.123^{b}$ & $3.05 \pm 0.221^{c}$ & $3.68 \pm 0.078^{\mathrm{bc}}$ & $3.08 \pm 0.028^{\mathrm{c}}$ \\
\hline Syringetin-3-O-galactoside & $4.25 \pm 0.569^{\mathrm{a}}$ & $3.28 \pm 0.249^{\mathrm{b}}$ & $2.06 \pm 0.116^{\mathrm{d}}$ & $2.64 \pm 0.084^{c}$ & $2.61 \pm 0.015^{\mathrm{c}}$ \\
\hline Syringetin-3-O-glucoside & $2.08 \pm 0.351^{\mathrm{a}}$ & $3.60 \pm 0.292^{\mathrm{b}}$ & $3.10 \pm 0.302^{c}$ & $3.48 \pm 0.039^{b c}$ & $3.22 \pm 0.160^{\mathrm{bc}}$ \\
\hline Total flavonols & $24.1 \pm 0.382^{\mathrm{a}}$ & $15.8 \pm 0.897^{\mathrm{b}}$ & $10.1 \pm 0.106^{\mathrm{c}}$ & $12.0 \pm 0.247^{\mathrm{d}}$ & $10.8 \pm 0.139^{\mathrm{c}}$ \\
\hline Procyanidin B1 & $19.5 \pm 1.32^{\mathrm{a}}$ & $24.6 \pm 1.68^{\mathrm{b}}$ & $14.9 \pm 0.422^{c}$ & $15.5 \pm 0.120^{\mathrm{c}}$ & $17.0 \pm 1.19^{\mathrm{a}}$ \\
\hline Epigallocatechin gallate & $2.87 \pm 0.064^{\mathrm{a}}$ & $2.78 \pm 0.085^{\mathrm{a}}$ & $2.88 \pm 0.336^{\mathrm{a}}$ & $3.12 \pm 0.045^{\mathrm{a}}$ & $4.84 \pm 0.650^{\mathrm{b}}$ \\
\hline Catechin & $15.9 \pm 1.19^{\mathrm{a}}$ & $5.38 \pm 0.526^{\mathrm{b}}$ & $4.22 \pm 0.776^{\mathrm{b}}$ & $4.95 \pm 0.282^{\mathrm{b}}$ & $4.51 \pm 0.557^{\mathrm{b}}$ \\
\hline Procyanidin B2 & $3.17 \pm 0.622^{\mathrm{a}}$ & $2.80 \pm 0.187^{\mathrm{a}}$ & $3.45 \pm 0.673^{\mathrm{a}}$ & $3.37 \pm 0.087^{\mathrm{a}}$ & $3.59 \pm 0.609^{\mathrm{a}}$ \\
\hline Epicatechin & ND & $2.20 \pm 0.136^{\mathrm{a}}$ & $3.06 \pm 0.134^{c}$ & $2.26 \pm 0.057^{\mathrm{a}}$ & $3.87 \pm 0.542^{\mathrm{b}}$ \\
\hline Total flavan-3-ol & $41.5 \pm 0.687^{\mathrm{a}}$ & $37.8 \pm 1.388^{\mathrm{b}}$ & $28.5 \pm 1.321^{\mathrm{c}}$ & $29.2 \pm 0.237^{\mathrm{c}}$ & $33.8 \pm 0.117^{\mathrm{b}}$ \\
\hline
\end{tabular}

ND: not detected. Values in the same row with different superscript letters are significantly different, $p=0.05$.

antioxidant activity; this value decreased after the drying process. Wines 1 and 2 obtained from the sweet juice had no significant differences, whereas wine 3 (totally fermented wine) presented the lowest value. Antioxidant activity has been related to phenolic compound and vitamin C. Some authors have found out that anthocyanins are the main compounds responsible for the antioxidant activity of berry fruits, and vitamin $\mathrm{C}$ affects this activity less. Specifically, a linear relation between total anthocyanins and antioxidant activity has been found in blueberry varieties [32] and others have found that vitamin $\mathrm{C}$ did not contribute to the antioxidant activity values in blueberries [33]. Some authors state that the antioxidant activity is closely related to compounds of high molecular weight $[34,35]$. In this work, the antioxidant activity decreased during the drying process and during the fermentation and there was no significant correlation between antioxidant activity, measured by the DPPH assay, and the composition of phenolic compounds, although there was a statistically significant relationship between antioxidant activity and vitamin C at the $99 \%$ confidence level, since the $p$ value in the ANOVA is less than 0.01 .

Figure 4 shows the scores obtained in the sensory analysis of the three wines. Wine 1 presented a more balanced score, standing out among others in terms of aroma. This can be due to the fact that the fermentation process was shorter, so varietal aromas were higher than in wine 2 and wine 3 . Wine 2 also presented an acceptable score for the tasters, standing out among the others in terms of flavor, as a result of the compensation between the acid flavor of the blueberry and the sweetness of a semisweet wine. On the other hand, in spite of having the worst score in flavor and aroma, wine 3 presented the best score in color, as a consequence of the highest contact time with the solid parts during the fermentation.

\section{Conclusions}

The winemaking of blueberry wines caused changes in color and concentration in bioactive compounds. The drying

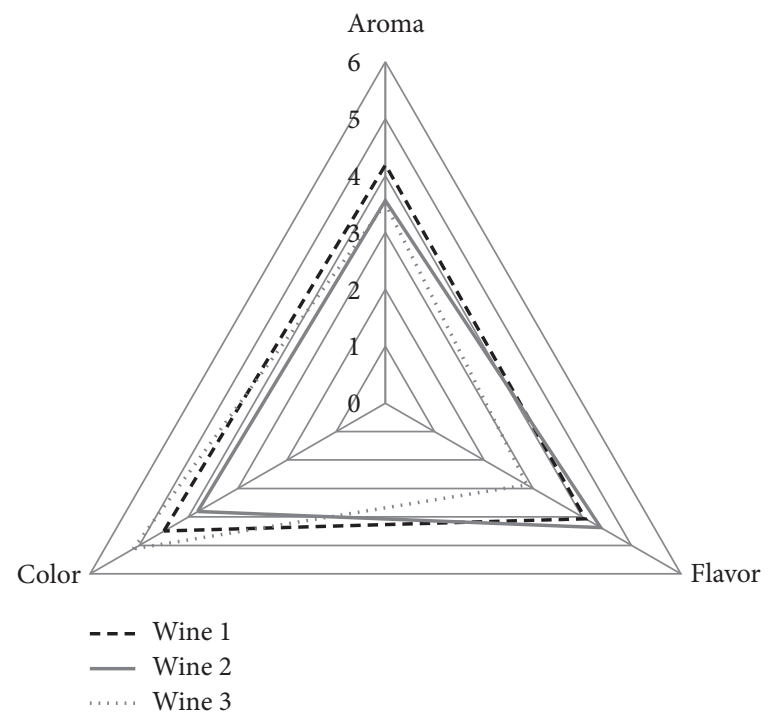

FIgURe 4: Sensory evaluation of the obtained wines.

process increased the absorbances at 420,520 , and $620 \mathrm{~nm}$, so the browning index and the contribution of red compounds were higher in the juice after drying. The concentration of anthocyanins and tannins also increased with drying; however, flavonols, flavan-3-ol derivatives, and vitamin C decreased in this stage. The fermentation stage caused a decrease in phenolic compounds, tannins, and antioxidant activity, while the concentration of vitamin $\mathrm{C}$ was constant. Wine 3 presented lower values of anthocyanins and tannins as well as antioxidant activity, in addition to high volatile acidity. The sensory analysis showed that partially fermented wines had the best score. In this sense, in the production of blueberry wines, the drying process is suitable to obtain juices rich in sugars; partial fermentation obtains better results than total fermentation. Further study on the drying stage as well as the fermentation could improve the characteristics of these wines. 


\section{Conflicts of Interest}

The authors declare that there are no conflicts of interest regarding the publication of this paper.

\section{References}

[1] J. G. Williamson and P. M. Lyrene, "Blueberry varieties for Florida," University of Florida. IFAS Extension, HS967, pp. 1-9, 2004.

[2] W. Routray and V. Orsat, "Blueberries and their anthocyanins: factors affecting biosynthesis and properties," Comprehensive Reviews in Food Science and Food Safety, vol. 10, no. 6, pp. 303320, 2011.

[3] Í. Arozarena, J. Ortiz, I. Hermosín-Gutiérrez et al., "Color, ellagitannins, anthocyanins, and antioxidant activity of andean blackberry (Rubus glaucus Benth.) wines," Journal of Agricultural and Food Chemistry, vol. 60, no. 30, pp. 7463-7473, 2012.

[4] H.-G. Yan, W.-H. Zhang, J.-H. Chen, and Z.-E. Ding, "Optimization of the alcoholic fermentation of blueberry juice by AS 2.316 Saccharomyces cerevisiae wine yeast," African Journal of Biotechnology, vol. 11, no. 15, pp. 3623-3630, 2012.

[5] M. H. Johnson, E. G. De Mejia, J. Fan, M. A. Lila, and G. G. Yousef, "Anthocyanins and proanthocyanidins from blueberryblackberry fermented beverages inhibit markers of inflammation in macrophages and carbohydrate-utilizing enzymes in vitro," Molecular Nutrition \& Food Research, vol. 57, no. 7, pp. 1182-1197, 2013.

[6] M.-S. Su and P.-J. Chien, "Antioxidant activity, anthocyanins, and phenolics of rabbiteye blueberry (Vaccinium ashei) fluid products as affected by fermentation," Food Chemistry, vol. 104, no. 1, pp. 182-187, 2007.

[7] S. Patel, "Blueberry as functional food and dietary supplement: The natural way to ensure holistic health," Mediterranean Journal of Nutrition and Metabolism, vol. 7, no. 2, pp. 133-143, 2014.

[8] V. R. De Souza, P. A. P. Pereira, T. L. T. Da Silva, L. C. De Oliveira Lima, R. Pio, and F. Queiroz, "Determination of the bioactive compounds, antioxidant activity and chemical composition of Brazilian blackberry, red raspberry, strawberry, blueberry and sweet cherry fruits," Food Chemistry, vol. 156, pp. 362-368, 2014.

[9] A.-N. Li, S. Li, Y.-J. Zhang, X.-R. Xu, Y.-M. Chen, and H.-B. $\mathrm{Li}$, "Resources and biological activities of natural polyphenols," Nutrients, vol. 6, no. 12, pp. 6020-6047, 2014.

[10] A. Castañeda-Ovando, M. de Lourdes Pacheco-Hernández, M. Elena Páez-Hernández, J. A. Rodríguez, and C. A. Galán-Vidal, "Chemical studies of anthocyanins: a review," Food Chemistry, vol. 113, pp. 859-871, 2009.

[11] R. Boulton, "The copigmentation of anthocyanins and its role in the color of red wine: A critical review," American Journal of Enology and Viticulture, vol. 52, no. 2, pp. 67-87, 2001.

[12] N. Mateus, S. Marques, A. C. Gonçalves, J. M. Machado, and V. De Freitas, "Proanthocyanidin composition of red Vitis vinifera varieties from the Douro valley during ripening: Influence of cultivation altitude," American Journal of Enology and Viticulture, vol. 52, no. 2, pp. 115-121, 2001.

[13] R. O. Santos, S. C. Trindade, L. H. Maurer, A. M. Bersch, C. K. Sautter, and N. G. Penna, "Physicochemical, antioxidant and sensory quality of Brazilian Blueberry Wine," Anais da Academia Brasileira de Ciências, vol. 88, no. 3, pp. 1557-1568, 2016.

[14] L. Zhang, N. Li, and X. Gao, "Phenolic compounds and antioxidant activity of wines fermented using ten blueberry varieties,"
American Journal of Food Technology, vol. 11, no. 6, pp. 291-297, 2016.

[15] H. Fu, L. Zhang, B. He, P. Yue, and X. Gao, "Analysis of organic acids in blueberry juice and its fermented wine by high performance liquid chromatography," Advance Journal of Food Science and Technology, vol. 9, no. 2, pp. 127-134, 2015.

[16] M. P. Serratosa, A. Lopez-Toledano, J. Merida, and M. Medina, "Changes in color and phenolic compounds during the raisining of grape Cv. Pedro Ximenez," Journal of Agricultural and Food Chemistry, vol. 56, no. 8, pp. 2810-2816, 2008.

[17] M. K. Krokida and Z. B. Maroulis, "Kinetics on color changes during drying of some fruits and vegetables," Drying Technology, vol. 16, no. 3-5, pp. 667-685, 1998.

[18] European Community, Official Journal L272 of October 1990, Mundi Prensa, Madrid, Spain, 1990.

[19] OIV, Collection of international methods of analysis of wines and musts, Organisation Internationale de laVigne et du vin, Paris, France, 2005.

[20] F. Alén-Ruiz, M. S. García-Falcón, M. C. Pérez-Lamela, E. Martínez-Carballo, and J. Simal-Gándara, "Influence of major polyphenols on antioxidant activity in Mencía and Brancellao red wines," Food Chemistry, vol. 113, no. 1, pp. 53-60, 2009.

[21] J. Lee, R. W. Durst, and R. E. Wrolstad, "Determination of total monomeric anthocyanin pigment content of fruit juices, beverages, natural colorants, and wines by the $\mathrm{pH}$ differential method: collaborative study," Journal of AOAC International, vol. 88, no. 5, pp. 1269-1278, 2005.

[22] E. A. Crowell and C. S. Ough, "A modified procedure for alcohol determination by dichromate oxidation," American Journal of Enology and Viticulture, vol. 30, pp. 61-63, 1979.

[23] A. Marquez, M. P. Serratosa, A. Lopez-Toledano, and J. Merida, "Colour and phenolic compounds in sweet red wines from Merlot and Tempranillo grapes chamber-dried under controlled conditions," Food Chemistry, vol. 130, no. 1, pp. 111-120, 2012.

[24] Official State Bulletin, Order of July 13, 2010, No. 169, Ed. Ministry of the Environment, and Rural and Marine Affairs, Madrid, Spain, 2010.

[25] A. Caridi, "New perspectives in safety and quality enhancement of wine through selection of yeasts based on the parietal adsorption activity," International Journal of Food Microbiology, vol. 120, no. 1-2, pp. 167-172, 2007.

[26] A. Marquez, M. P. Serratosa, and J. Merida, "Anthocyanin evolution and color changes in red grapes during their chamber drying," Journal of Agricultural and Food Chemistry, vol. 61, no. 41, pp. 9908-9914, 2013.

[27] A. Marquez, M. P. Serratosa, and J. Merida, "Pyranoanthocyanin derived pigments in wine: Structure and formation during winemaking," Journal of Chemistry, vol. 2013, Article ID 713028, 15 pages, 2013.

[28] F. He, N.-N. Liang, L. Mu et al., "Anthocyanins and their variation in red wines II. Anthocyanin derived pigments and their color evolution," Molecules, vol. 17, no. 2, pp. 1483-1519, 2012.

[29] C. Dhuique-Mayer, M. Tbatou, M. Carail, C. Caris-Veyrat, M. Dornier, and M. J. Amiot, "Thermal degradation of antioxidant micronutrients in Citrus juice: kinetics and newly formed compounds," Journal of Agricultural and Food Chemistry, vol. 55, no. 10, pp. 4209-4216, 2007.

[30] Z. Guadalupe and B. Ayestarán, "Changes in the color components and phenolic content of red wines from Vitis vinifera L. Cv. "tempranillo" during vinification and aging," European Food Research and Technology, vol. 228, no. 1, pp. 29-38, 2008. 
[31] I. Budić-Leto, T. Lovrić, J. G. Kljusurić, I. Pezo, and U. Vrhovšek, "Anthocyanin composition of the red wine Babic affected by maceration treatment," European Food Research and Technology, vol. 222, no. 3-4, pp. 397-402, 2006.

[32] J. C. Mi, L. R. Howard, R. L. Prior, and J. R. Clark, "Flavonoid glycosides and antioxidant capacity of various blackberry, blueberry and red grape genotypes determined by highperformance liquid chromatography/mass spectrometry," Journal of the Science of Food and Agriculture, vol. 84, no. 13, pp. 1771-1782, 2004.

[33] G. Borges, A. Degeneve, W. Mullen, and A. Crozier, "Identification of flavonoid and phenolic antioxidants in black currants, blueberries, raspberries, red currants, and cranberries," Journal of Agricultural and Food Chemistry, vol. 58, no. 7, pp. 3901-3909, 2010.

[34] N. Tlili, H. Mejri, F. Anouer, E. Saadaoui, A. Khaldi, and N. Nasri, "Phenolic profile and antioxidant activity of Capparis spinosa seeds harvested from different wild habitats," Industrial Crops and Products, vol. 76, pp. 930-935, 2015.

[35] A. Marquez, M. P. Serratosa, and J. Merida, "Antioxidant activity in relation to the phenolic profile during the winemaking of sweet wines Vitis vinifera cv. Cabernet Sauvignon," International Journal of Food Science \& Technology, vol. 49, no. 9, pp. 21282135, 2014. 

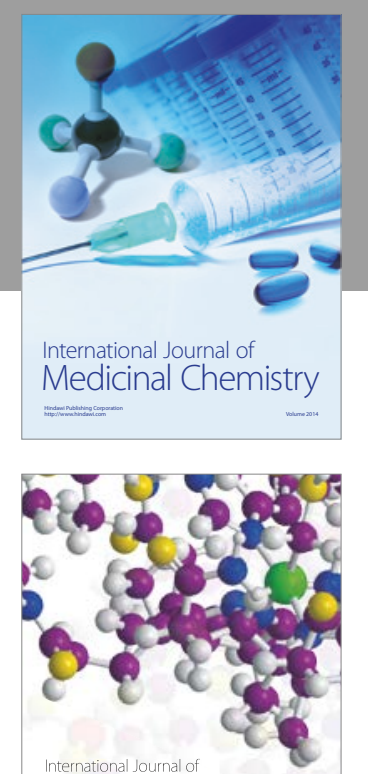

Carbohydrate Chemistry

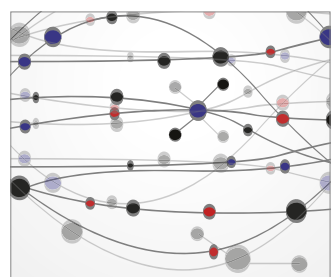

The Scientific World Journal
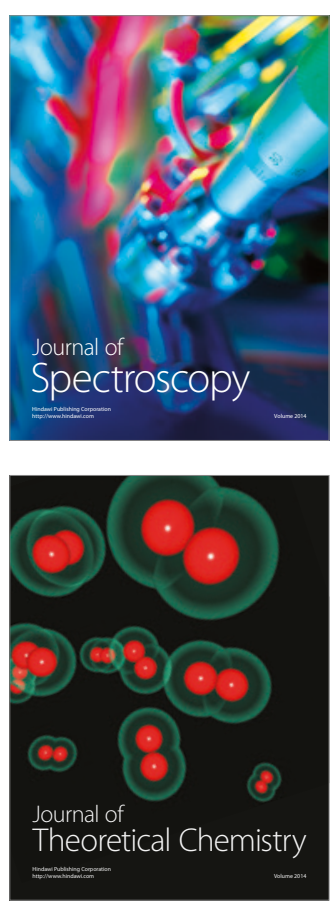
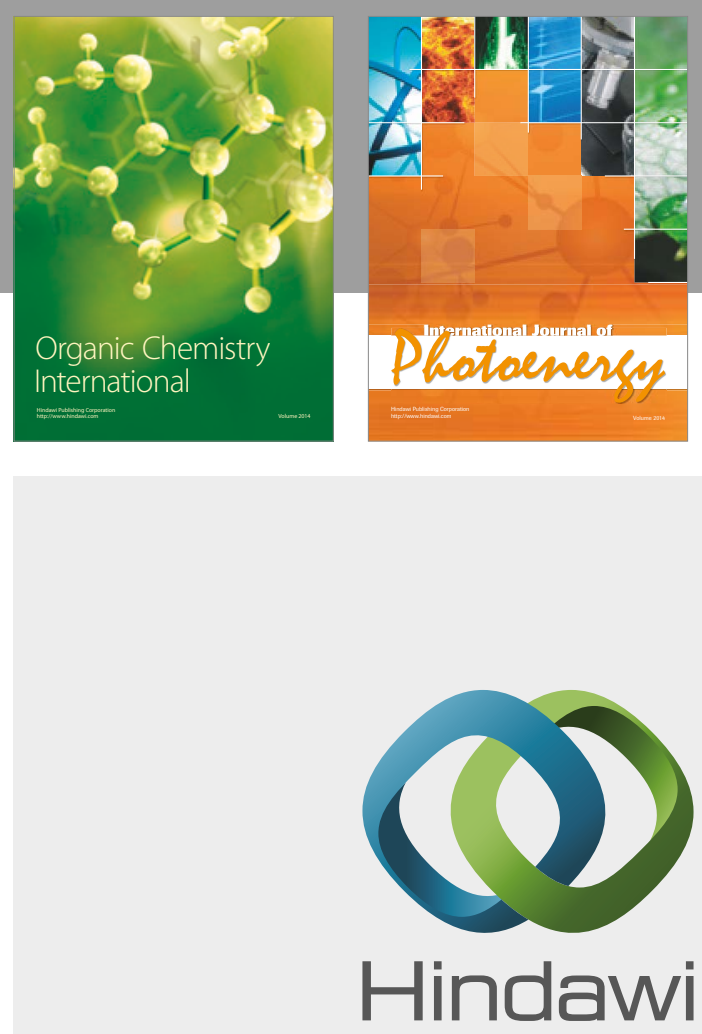

Submit your manuscripts at

https://www.hindawi.com

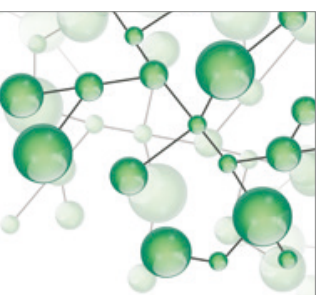

International Journal of

Inorganic Chemistry

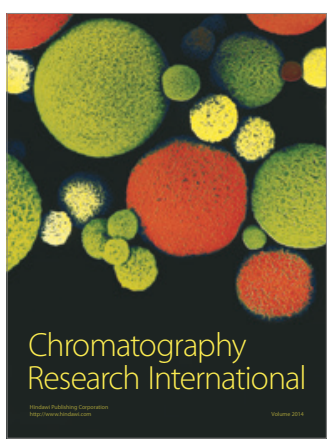

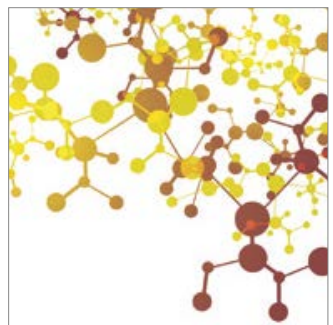

Applied Chemistry
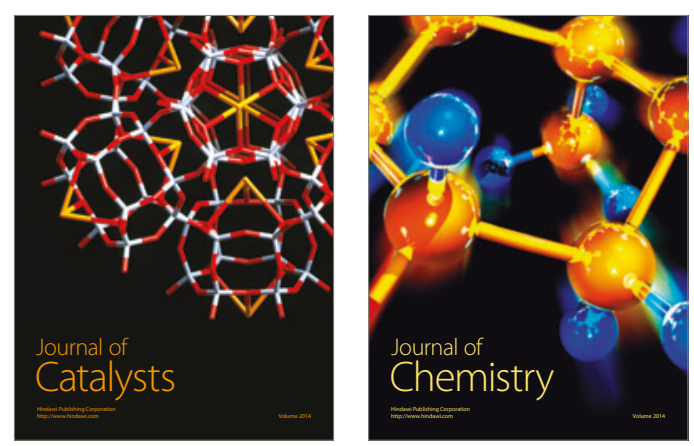
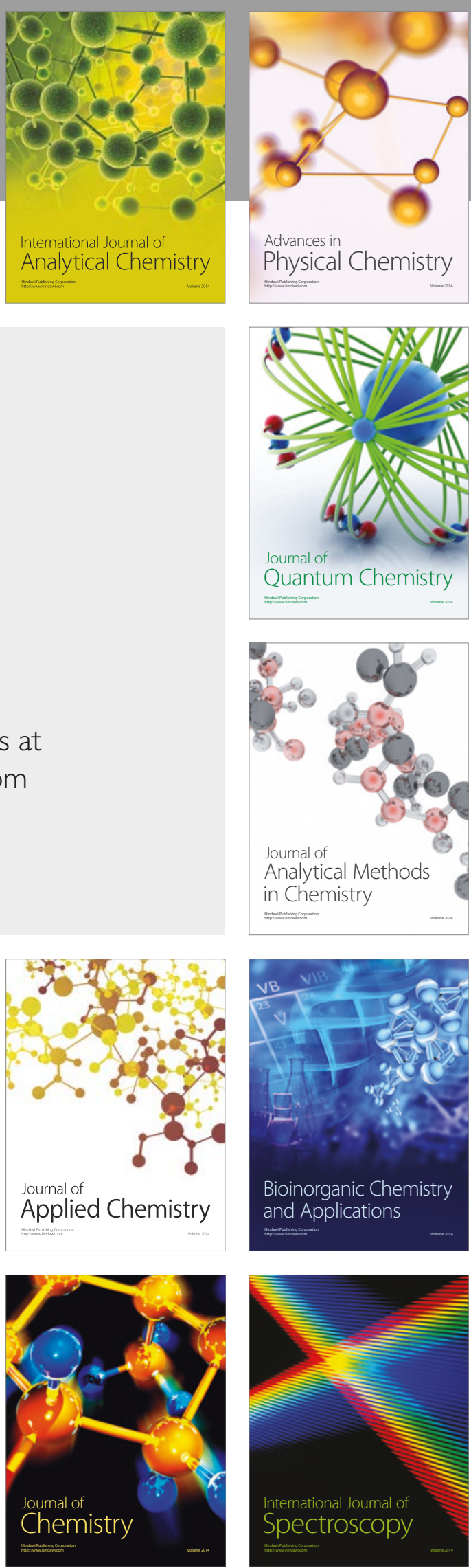